revista do ieb n 46 p. 201-216 fev 2008

\title{
Através do Brasil com Afonso Arinos
}

Ricardo Souza de Carvalho ${ }^{1}$

\section{Resumo}

A figura de Afonso Arinos, restringida ao tópico da ficção regionalista, é reabilitada neste artigo como primordial no movimento nacionalista das letras do final do século XIX e das primeiras décadas do XX. 0 estímulo que provocou em dois escritores de gerações diferentes - o contemporâneo Olavo Bilac e o moço em início de carreira Mário de Andrade - pode revelar que as divisões da história literária nem sempre dão conta das continuidades e das rupturas.

\section{Palavras-chave}

Afonso Arinos, nacionalismo, Olavo Bilac, Mário de Andrade. 
revista do ieb n 46 p. 201-216 fev 2008

\title{
Travelling through Brazil with Afonso Arinos
}

Ricardo Souza de Carvalho

\begin{abstract}
Afonso Arinos' role, restricted to the topic of the regionalistic fiction, is rehabilitated in this article as primordial in the nationalistic movement of the end of XIXth century and the first decades of the XXth century. The motivation that he gave to two writers from different generations - the contemporary Olavo Bilac and the young Mário de Andrade, in the beginning of his career - enables us to show that the divisions of literary history not always give account of continuities and ruptures.
\end{abstract}

\section{Keywords}

Afonso Arinos, nationalism, Olavo Bilac, Mário de Andrade. 


\section{Caçando esmeraldas pelo interior do Brasil}

Afonso Arinos conheceu Olavo Bilac em 1893, na cidade de Ouro Preto, ainda capital de Minas Gerais, iniciando uma amizade que seguiria pela vida afora. Arinos, de 25 anos, exercia ali a advocacia desde 1891, mas a atração pela História que o cercava fez com que passasse a fazer pesquisas em fontes documentais, base de vários de seus futuros trabalhos. Já Bilac, de 28 anos, vinha exilado do Rio de Janeiro, onde chegou a ser preso por sua posição contrária ao governo de Floriano Peixoto, mas trazia na bagagem o êxito das Poesias publicadas em 1888. Passados dez anos, Bilac evocou, no discurso de recepção a Arinos na Academia Brasileira de Letras, a singularidade do encontro:

[...] Tivemos ali meses de uma vida singular, intensamente vivida, cheia de completos prazeres intelectuais, - que só podem ser bem contados aqui, a uma assistência escolhida e culta como esta, capaz de compreender como dois homens em pleno viço da mocidade puderam passar semanas e semanas entre os vivos, não os vendo nem ouvindo, e só tendo ouvidos e olhos para um estranho mundo de sombras e de fantasmas. ${ }^{2}$

Conduzido pela mão de Arinos, Bilac freqüentou o Arquivo Público Mineiro, reabilitado graças ao amigo. Sugestivas imagens, motivadas pela aventura da expansão colonizadora, foram despertadas em Bilac pelo contato com o passado brasileiro:

[...] Entrávamos, com respeito, abafando o pisar; e, assim que começávamos a folhear os grossos livros encapados em couro, uma poeira sutil começava a encher o imenso e triste salão. Foi ali que respirei largamente isso a que o mais desmoralizado dos chavões dá o nome de pó dos séculos... Era um pó que parecia sair do fundo dos ossuários remexidos, um pó impalpável e invisível que era como o bafo úmido e tênue do respirar dos in-fólios comidos das traças. À medida que íamos virando as páginas, cobertas de uma escritura quase hieroglifica, miudinha e certa, retalhada de barras caprichosas, com fantasias de recorte nas maiúsculas e voltas faceiras nas vírgulas acaramujadas, as nossas impressões exteriorizavam-se; e, no pó finíssimo que pairava em torno de nós, percebíamos vagos cheiros indefinidos, que se casavam ou contrastavam, harmonizando-se, como as notas de uma concertina de aromas: havia o cheiro fresco dos vales, das montanhas, dos ribeirões de águas cantantes, de todo aquele seio de natureza

2 ACADEMIA BRASILEIRA DE LETRAS. Discursos acadêmicos: 1897-1919. Rio de Janeiro: ABL, 2005. t. 1, v. 1-4. p. 162. 
virgem pesquisado pelas caravanas da conquista; o cheiro úmido de terra cavada, e das gupiaras cheias de gorgulho; o cheiro apagado e caricioso do incenso das sés e das sacristias; o cheiro da mandioca macerada com que as damas faziam brancos os cabelos... E, não raro, subia e dominava todos os outros um cheiro acre de sangue, uma exaltação de mortualhas podres, de cadáveres de mineiros soterrados nas minas, de garimpeiros rebeldes esquartejados pela justiça, de pretos famintos e de reinóis insubordinados, corridos a pontaços de lança pelos dragões de El Rei... ${ }^{3}$

Recentemente, Antonio Dimas, no artigo "Entre Vila Rica e Belo Horizonte”, realça a importância de Arinos como uma "espécie de professor de Brasil para Bilac":

Num espaço convidativo, favorável ao recolhimento e à evocação, dava-se o encontro entre pessoas certas. Nesse lugar e nesse momento operava-se o batismo (ou seria conversão?) de um intelectual que, até então, granjeara sua notoriedade graças às musas helênicas. Antecipando futuras conversões dos modernistas, nos anos de 1910 e 1920, com Mário de Andrade à frente, a antiga Vila Rica abocanhava um poeta parnasiano e o transformava em historiador informal, em perspectiva ligeiramente diferente de seu conversor Arinos, no entanto. Enquanto o escritor mineiro construía e consolidava seu nacionalismo com base numa exploração "geográfica" e, portanto, "espacial" do Brasil, Bilac articulava o seu nacionalismo inicial a partir de uma perspectiva "histórica” e, portanto, “temporal”. Em resumo: Arinos preferiu o regionalismo; Bilac optou pelo historicismo. ${ }^{4}$

Nos anos seguintes, Arinos publicaria em periódicos os contos em que focaliza a paisagem e o homem do interior, reunidos no livro Pelo Sertão, de 1898. Quanto a Bilac, o fruto mais imediato do frescor nacionalista oferecido por Arinos foi o poema "O Caçador de Esmeraldas", idealizado ainda na estada em Ouro Preto - Arinos lembraria os "passeios solitários pelas ruínas de Vila Rica, de onde surgiram tantas admiráveis Crônicas e Novelas e as páginas épicas do Caçador de Esmeraldas" ${ }^{2}$ - , e acrescido na

3 ACADEMIA BRASILEIRA DE LETRAS. Discursos acadêmicos: 1897-1919. Rio de Janeiro: ABL, 2005. t. 1, v. 1-4, p. 163.

4 DIMAS, Antonio. Bilac, o jornalista: ensaios. São Paulo: EDUSP, Imprensa Oficial; Campinas: Editora da Unicamp, 2006. p. 77.

5 ARINOS, Afonso. A Olavo Bilac. [Carta não datada] do Arquivo de Afonso Arinos. Revista do Livro, Rio de Janeiro, ano 4, n. 16, p. 145-147, dez. 1959. p. 147. 
$2^{a}$ edição de Poesias, de 1902. Apesar do sopro épico da busca de Fernão Dias Paes às esmeraldas, a reduzida dimensão do "Caçador de Esmeraldas” - 46 sextilhas em versos alexandrinos - faz pensar em um "minimalismo épico", segundo Ivan Teixeira:

[...] Trata-se de uma espécie de recorte metonímico da história colonial, traço que Bilac deve ter aprendido com Basílio da Gama, cujo Uruguay se impõe como verdadeira obra-prima da brevidade e da concisão [...]. A exemplo de tantos poetas inferiores a ele, Bilac talvez pudesse tentar um poema épico de grandes dimensões. Todavia, deteve-se às reduzidas proporções que se conhecem, deixando em cada verso a marca lapidar da perfeição de seu ofício. ${ }^{6}$

Nas estrofes finais, em meio ao delírio de Fernão Dias Paes à beira da morte, escuta-se uma voz - espécie de sentença da narrativa - que compensa a ambição vã pela expansão das fronteiras da pátria, história da conquista "geográfica" de Arinos e de tantos outros regionalistas:

Morre! morrem-se às mãos as pedras desejadas, Desfeitas como um sonho, e em lodo desmanchadas... Que importa? dorme em paz, que o teu labor é findo! Nos campos, no pendor das montanhas fragosas, Como um grande colar de esmeraldas gloriosas, As tuas povoações se estenderão fulgindo!

[...]

E, subjugando o olvido, através das idades, Violador de sertões, plantador de cidades Dentro do coração da pátria viverás! ${ }^{7}$

A carreira ilustre desses versos, os quais serviram para mais de um arroubo patriótico - no tempo em que ainda se recitava Bilac -, calou fundo também em Mário de Andrade. Mesmo tendo composto os poemas de Paulicéia desvairada e em pleno acerto de contas com os parnasianos, reconhece no poema bilaquiano a "realização completa da Beleza". Após ter dissecado Francisca Julia, Raimundo Correia e Alberto de Oliveira, a série "Mestres do Passado" para o Jornal do Comércio de 1921 atingia

6 TEIXEIRA, Ivan. Prefácio. In: BILAC, Olavo. Poesias. São Paulo: Martins Fontes, 2001. p. XLI.

7 BILAC, Olavo. op.cit. p. 262-263. 
Bilac. No entanto, Mário não vê "0 Caçador de Esmeraldas" apenas como realização do Belo, mas valoriza-lhe a mensagem nacionalista, que, por sua vez, marcaria o trabalho posterior do autor modernista:

Bilac quando chegou a essa parte do poema estava comovido. Incendiavam-lhe o espírito os arremessos de amor da pátria, sentimento em que foi constante e sincero toda a vida. A perfeição dos versos continuou porque a sua técnica era tal que todas as suas comoções eram já metrificadas, com exatidão, rimadas com abundância. E o fim do seu poemeto é colossal. E foi nele, muito mais do que no soneto "Pátria", [...], e mais do que nos livros escolares, que o seu sincero patriotismo teve a melhor ocasião de se manifestar poeticamente. ${ }^{8}$

Voltando a Arinos, apesar da distância, ele continuou sendo uma referência para Bilac na busca do nacionalismo e na crítica aos arremedos vindos do estrangeiro. Ao ler em Paris uma notícia no jornal Temps, Arinos logo se lembrou do amigo no Rio de Janeiro que desde 1899 exercia o cargo de inspetor de escola:

Trata-se de uma novidade francesa ou antes parisiense e esta das mais finas, úteis e profícuas na educação estética de uma meninada como a brasileira, cuja curiosidade é tão viva e tão acessível às diversas formas da arte. Como vês, é a arte na escola primária, a boa arte sem grandes dispêndios e sem ostentação de mau gosto, abrindo-se maravilhosa aos olhares dos petizes numa sucessão dos grandes mestres, reproduzidos pela gravura, e de paisagens, onde a natureza da pátria se revela em todo o esplendor de sua sadia beleza. Não achas, meu caro Bilac, que com os nossos recursos podemos fazer algo nessa direção?

Como não é de estranhar num povo jovem, nós imitamos muito. Imitamos as mais das vezes a aparência, o exterior, porque não podemos apreender o fundo; outras vezes imitamos mal, querendo - estúpida vaidade - por basófia de progresso e civilização transportar para o nosso país leis, instituições e costumes que é impossivel se adaptarem ao nosso meio. ${ }^{9}$

8 BRITO, Mário da Silva. História do modernismo brasileiro, 1: antecedentes da Semana de Arte Moderna. 6. ed. Rio de Janeiro: Civilização Brasileira, 1997. p. 282 .

9 ARINOS, Afonso. A Olavo Bilac. [Carta não datada] do Arquivo de Afonso Arinos. Revista do Livro, Rio de Janeiro, ano 4, n. 16, p. 145-147, dez. 1959. p. 147. 
No que se refere às obras escritas e lidas, o cenário para as crianças entre nós começava a melhorar: o próprio Bilac vinha-se dedicando desde 1895 aos livros didáticos, ora em colaboração com Coelho Neto, ora com Manoel Bonfim, com quem escreveria uma de suas mais importantes realizações nesse terreno, Através do Brasil (1910) ${ }^{10}$. Continuação, em um plano mais "prático", ou ainda, "prosaico", do caminho iniciado por "O Caçador de Esmeraldas", visava a incutir o civismo e educar os pequenos, tanto em matéria de geografia, quanto de história. Para tal tarefa é que Olavo Bilac pediu ajuda a Arinos, em carta de 28 de janeiro de 1895:

[...] Meti ombros a uma empresa formidável, que me está ensopando de suor as barbas e a alma. Imagina que se trata disto: fazer um livro de contos (educação cívica!!!!) que possa ser adotado como livro de leitura nas escolas.

Calcula: fazer literatura que as crianças entendam e que, ao mesmo tempo, não seja fancaria! Oh! Estou acabrunhado já, e faze idéia: apenas dois contos estão feitos!

É para esse livro que preciso de ti, meu velho, meu bom, meu grande Afonso: quero que me escrevas quanto antes, mandandome esta informação:

Conheces bem Diamantina? Bem! Estabelecido o fato de haver em Diamantina ou Tijuco, em mil setecentos e tanto, um jardim de luxo, que árvores fruteiras ou de ornato achas tu que, com mais abundância, deveria haver nesse jardim? E, alargando mais a pergunta: podes mandar-me uns seis ou sete nomes das árvores, dos frutos, das flores mais comuns nesta região? - Tem paciência, Py y Camacho! Olha que se trata da glória da tua terra! ${ }^{11}$

0 pedido era plenamente viável, pois Arinos, em suas andanças pelo interior de Minas como "turista aprendiz", anotava o que via, da flora aos versos dos cantadores, em uma escrita telegráfica e sugestiva, moderna avant la lettre, bem diferente de

10 Além de publicar em 1904 as Poesias infantis, juntamente com Coelho Neto, elaborou Contos pátrios (1904) e Teatro infantil (1905). Ver LAJOLO, Marisa. Usos e abusos da literatura na escola: Bilac e a literatura escolar na República Velha. Rio de Janeiro: Globo, 1982.

11 BILAC, Olavo. De Olavo Bilac. [Carta] do Arquivo de Afonso Arinos. Revista do Livro, Rio de Janeiro, ano 4, n. 16, p. 165-166, dez. 1959. p. 165. 
certos momentos de seus contos dados à imprensa, devedores do pendor rebuscado da época:

[...] Diferença da paisagem e da flora. Cerradão. Capa rosa, barbatimão, sucupira, (favas medicinais) angico, aroeira, pau-munjolo ou sucupira branca, bosque de mimosas, aroerinha (euphorbia) coroíba com cachos de flores amarelas, pau d'óleo, cedro, faveira (árvore que se presta a arborização). Quando mais se desce mais fértil se torna o terreno. Mandapuçá - fruta como a jaboticaba, que dá grudada ao tronco e é muito saborosa. A sua cor é pardoescuro. Mangabeiras, bacuparis, mutamba. Pé-de-pinto, que o povo não queima, por superstição. Cactus. Flor de cobra (esponja) que o povo não apanha por causa das cobras. ${ }^{12}$

Sem ir longe demais e vislumbrar aqui um laboratório do que Guimarães Rosa faria em sua ficção, fiquemos com a imagem de um Bilac que encontrou em Arinos as palavras da terra para ensinar aos meninos do Brasil.

\section{Lendas e tradições brasileiras em São Paulo}

Enquanto o Rio de Janeiro estava saturado pela moda das conferências, iniciada aliás por Bilac, seria a vez de Arinos levá-la em 1915 a São Paulo, que já se destacava pela indústria e pelo aumento de sua população. E a vida cultural deveria acompanhar esse surto de desenvolvimento, ainda que copiando os modismos da Capital Federal: a Sociedade de Cultura Artística, fundada em 1912, convidava ilustres escritores para recitais e conferências, como Arinos para a série intitulada "Lendas e tradições brasileiras”, seis falas que terminaram com apresentações no Teatro Municipal. E essa foi sua última grande atuação, já que faleceria repentinamente no ano seguinte no exterior. Em 1917, as conferências foram reunidas em livro com o mesmo título, contendo um prefácio em que Bilac registra a última homenagem ao amigo: “[...] Viajador da nossa terra, familiar do sertão e dos sertanejos, ele teve o dom de tratar os homens de alma simples, sabendo falar-lhes e ouvi-los e enternecendo-se com o seu sonho rústico." ${ }^{13}$ Por falar em Bilac, como Arinos, o poeta também percebeu

12 ARINOS, Afonso. Notas de viagem [do] Arquivo de Afonso Arinos. Revista do Livro, Rio de Janeiro, ano 4, n. 16, p. 155-159, dez. 1959 p. 156.

13 Idem. Lendas e tradições brasileiras. São Paulo: Tipografia Levi, 1917. p. V. 
que não podia deixar de fora os paulistanos nesse 1915, viajando então a São Paulo em sua campanha do serviço militar obrigatório. Foi recebido com entusiasmo pelos estudantes do Largo de São Francisco, chegando a travar contato com o aspirante a literato Oswald de Andrade, o qual já lançara no início desse ano tão movimentado um brado, ao estilo de Arinos e Bilac, no artigo "Em prol de uma pintura nacional".

Além do mais, não nos devemos esquecer da profunda relação que Arinos manteve com a capital paulista: como estudante de Direito no Largo de São Francisco, entre 1885 e 1889; como diretor da folha monarquista O Comércio de São Paulo, em 1897, na qual publicou em folhetim a primeira obra a respeito da Guerra de Canudos, o romance Os jagunços; e pelo casamento, nesse mesmo ano, com Antonieta Prado, sobrinha de Eduardo Prado e filha do conselheiro Antonio Prado.

No auge da Primeira Guerra Mundial, em que os brios nacionalistas andavam acirrados, juntamente com o prestígio de Arinos, pode-se ter uma idéia do entusiasmo que despertaram as conferências sobre cultura popular e história do Brasil. Na platéia, encontrava-se um jovem de 22 anos, sócio fundador da Sociedade de Cultura Artística, que provavelmente se impressionou com o mundo descortinado por Arinos. Embora, ao que se saiba, em nenhum ponto de sua obra Mário de Andrade se tenha manifestado sobre essas conferências de Arinos, elas podem ser apontadas como o início mais plausível do seu intenso trabalho no estudo e divulgação da cultura brasileira. A presença de Arinos ainda se prolongaria a ponto de, no ano da Semana de Arte Moderna, Tristão de Athayde dedicar-lhe um livro, assim se manifestando a respeito das conferências "Lendas e tradições brasileiras":

É preciso tê-las ouvido, nesse ambiente peculiar de S. Paulo, onde palpita a grande energia do Brasil de amanhã ligada à seiva do Brasil de ontem, para compreender o alcance e a repercussão dessas formosas palavras do coração. ${ }^{14}$

0 que parecia novidade a um público saturado da moda e das idéias de Paris - ainda longe das correntes de vanguarda, mas tributária dos resquícios da Belle Époque - não constituía descoberta de Arinos. Desde nossos românticos, na tarefa de construção de uma arte nacional, a cultura popular e a pesquisa do folclore vinham sendo valorizadas. José de Alencar - diga-se

14 ATHAYDE, Tristão de. Afonso Arinos. 2. ed. São Paulo: LISA; Brasília: INL, 1981. p. 79. 
de passagem, um dos grandes modelos para o nacionalismo de Arinos -, na série de cartas dirigidas ao amigo Joaquim Serra, "O Nosso Cancioneiro", de 1874, sinalizava essa vereda a ser seguida: "É nas trovas populares que sente-se mais viva a ingênua alma de uma nação." ${ }^{15}$ Entre os vários trabalhos e coletâneas de peças populares no entre-séculos, destacam-se os de Silvio Romero: Cantos populares do Brasil (1883), Contos populares do Brasil (1885) e Estudos sobre a poesia popular no Brasil (18701880), publicados em volume em 1888.

Logo na primeira conferência, em fevereiro, Arinos incita os ouvintes para a riqueza da cultura popular como estímulo para a arte erudita, lição amplamente aproveitada pelos autores modernistas anos mais tarde:

[...] venho apenas chamar a vossa atenção para a existência desse opulento tesouro esquecido e não farei mais do que indicar o vieiro. Explorai-o, colhei a mancheias, que tocareis na fonte verdadeira da vida da nossa raça e ela repetirá convosco o milagre de Fausto.

Poetas, inspirai-vos ali, que sereis para o vosso povo, verdadeiros 'vates', isto é, profetas! Compositores, buscai a melodia popular e ela vos dará, com a originalidade e a força, glória e fama imortais. ${ }^{16}$

Muito do que Arinos estava oferecendo ao público paulistano, ele mesmo ouviu da boca do povo, em suas andanças pelo sertão mineiro, não deixando de registrar os nomes e seus saborosos apelidos:

[...] A anhuma é ave sábia e santa, que benze a água antes de bebê-la e tem, ao crepúsculo, um canto de infinita saudade e doçura para o sertanejo. Não há bom violeiro que não conheça o lundu da anhuma. Tive a dita de ouvi-lo cantado em diálogo por dois admiráveis trovadores de Paracatu - o Martiniano do Riachão, e o Antonio Farinha-seca, os quais se não tem os implumados gorros, os talabartes e os espadins dos seus colegas da idade-média, não tem menos sentimento e expressão. ${ }^{17}$

15 ALENCAR, José de. 0 nosso cancioneiro. Edição de Maria Eurides Pitombeira de Freitas. Campinas, SP: Pontes, 1993. p. 19.

16 ARINOS, Afonso. Lendas e tradições brasileiras. São Paulo: Tipografia Levi, 1917. p. 5.

17 Ibid. 22-23. 
E assim como antes alertara Bilac para o perigo da imitação do estrangeiro, convidava então os moços de São Paulo - por que não pensar, além de Mário de Andrade, em Oswald de Andrade, Guilherme de Almeida e Cassiano Ricardo? - a se voltarem ao Brasil:

A desventura alheia nos aconchega uns aos outros. Aproveitemos desse momento para nos conhecermos.

Durante um século estivemos a olhar para fora, para o estrangeiro: olhemos agora para nós mesmos.

Quantas vezes a vária Fortuna esconde junto de nós aquilo que com renitente afã buscamos ao longe. ${ }^{18}$

As conferências seguintes mostram bem a variedade almejada por Arinos: "As amazonas e o seu rio; as Iaras" (fevereiro); "O São Francisco e suas lendas; a Serra das Esmeraldas; as minas de prata; o caboclo d'água" (março); "A capela da montanha; Algumas igrejas do Brasil e suas tradições" (abril); "0 culto de Maria nos costumes, na tradição e na história do Brasil” (julho); e "Santos populares; Superstições; Festas e danças" (dezembro).

0 mais impressionante estava reservado para o final. Após a última conferência de Arinos, houve a apresentação de "festas tradicionais brasileiras", em pleno palco do Teatro $\mathrm{Mu}-$ nicipal, inaugurado há pouco, em 1911, aos moldes dos grandes teatros europeus, para que a elite paulistana pudesse desfrutar dos espetáculos de ópera e de balé. 0 Programa, que viria como anexo da edição de Lendas e tradições brasileiras de 1917, também pode ser visto como o primeiro exemplar da série de programas musicais conservados por Mário de Andrade ${ }^{19}$, o que indica a sua presença no espetáculo.

0 que na década seguinte veria in loco em suas viagens pelo Norte e Nordeste, Mário pôde vislumbrar sem sair de São Paulo: Loas de Natal e Reis, A Marujada, Reisado das Borboletas, Pinica-pau, Bumba-meu-boi, Cateretê do Norte e Lundu do Sul. Como prova de que as palavras de Arinos surtiram efeito, a distribuição dos papéis obteve "imediatamente na alta sociedade de S. Paulo o mais generoso e entusiástico apoio". Assim, entre as Borboletas, surgia uma Maria Guedes Penteado, entre

18 ARINOS, Afonso. Lendas e tradições brasileiras. São Paulo: Tipografia Levi, 1917. p. 30.

19 Série Programas Musicais, Arquivo Mário de Andrade, IEB-USP. 
os Marinheiros, um Eduardo da Silva Prado, entre as Pastoras, uma Maria de Lourdes Magalhães Castro, e entre os Pastores, um Julio Mesquita Filho. Todos acompanhados pelos músicos reunidos por João Guimarães, mais conhecido como Pernambuco, vindo do Rio de Janeiro especialmente para o evento. Sem que se arrisque a adivinhar como se teriam saído os moços e as moças das famílias mais tradicionais da cidade em seus papéis rústicos, o fato é que houve uma momentânea quebra na rotina cultural. A cultura popular, ainda que se tenha estilizado para o paladar do público, chegava ao templo da cultura erudita. Em 1922, no mesmo Teatro Municipal e patrocinado pela mesma elite, seria a vez de se atualizar essa tradição com as formas das vanguardas européias aclimatadas. Mas isso é outra história. No momento, basta acompanhar as realizações de Mário a partir das conferências de Arinos e dessas apresentações até às vésperas da Semana de Arte Moderna.

Na esteira de Pelo sertão, Mário ensaiou a narrativa regionalista em "Caçada de macuco" (1917) e "Caso pansudo" $(1918)^{20}$. Paralelamente, ainda em 1917, tempos de guerra, saudou Elói Chaves, secretário da Justiça do governo paulista, que discursava no Conservatório Dramático Musical a favor de uma participação do Brasil no conflito:

[...] a pátria é e deve existir para nós não como o desenvolvimento duma filosofia no pensamento, mas como o desenvolvimento dum amor dentro do coração! Pátria é a saíra que singra o azul de São Paulo; é a onda esbatendo-se contra os rochedos da Guanabara; é a carnaúba flamulando ao vento nas restingas adustas do Ceará! Pátria é a gurara para o Norte, Curupaiti no Sul! São essas grandes matas - movimentos verdes - onde os Pais Leme deixaram as suas ossadas junto às pedras de luz viva! É a conjugação das três raças tristes donde saiu esta nacionalidade inda em botão - forte e dura - vencedora de tantas intempéries diversas! Enfim é o lar onde encontramos cada dia os retratos plácidos dos nossos avós olhando em pasmo, as cabeças branquecidas de nossas mães! Lar onde se distenderá pela imensidade de tanto sertão inda inculto a atividade salvadora dos nossos filhos!... ${ }^{21}$

20 [Reunidos em 1925 em Primeiro andar]. ANDRADE, Mário de. Obra imatura. 3. ed. São Paulo: Martins; Belo Horizonte: Itatiaia, 1980.

21 BRITO, Mário da Silva. História do modernismo brasileiro, 1: antecedentes da Semana de Arte Moderna. 6. ed. Rio de Janeiro: Civilização Brasileira, 1997. p. 68. 
Primeiro registro que temos do "sentimento nacional" de Mário, aproxima-se muito do estilo das conferências de "Lendas e tradições brasileiras". 0 historiador Mário da Silva Brito, em nota ao trecho citado acima, afirma que a "alusão a Fernão Dias e às três raças tristes trai a origem bilaqueana do pensamento de Mário de Andrade". Eu acrescentaria que, nesse momento, Mário retomava as representações estéticas e ideológicas não só de Bilac, mas também de seu promotor inicial, Afonso Arinos. Aliás, não há menção alguma às conferências de Arinos nos "antecedentes" da fundamental história do Modernismo realizada por Silva Brito.

A primeira viagem de descobertas para Mário, já imbuído desse espírito nacionalista, deu-se em 1919 por Minas Gerais, detendo-se nas cidades históricas. Dela resultou a série de artigos "A arte religiosa no Brasil", publicada no ano seguinte na Revista do Brasil ${ }^{22}$.

Mas a presença das vanguardas já se fazia sentir. Em 27 de maio de 1921, Oswald publicou alguns versos que integrariam Paulicéia desvairada, sob o título "Meu poeta futurista", no Jornal de Comércio. Diante das reações provocadas, Mário respondeu no mesmo periódico a 6 de julho - "Futurista!?", em que não apenas rejeita o rótulo, como também afirma seu apego à tradição:

Algumas idéias dele pude muito bem compreender ou distinguir; mas estas horrorizam: o banimento completo da lembrança de Deus, o desrespeito pelo meigo idioma, também gentil, e o abandono das noções de pátria e principalmente de tradição...

[...] E amamos de inconsuntivel amor estes chãos larguíssimos de onde vimos a luz; e estremecemos a pátria, não pelo que é, nem pelo que será, mas pelo que já foi. ${ }^{23}$

Embora já experimente certas rupturas próprias das vanguardas, quando tem de prestar contas ao público mais conservador Mário insiste ainda na retórica de Arinos e Bilac. Mas se um estilo vai ser abandonado em favor do coloquialismo promovido pelo Modernismo, um projeto fica para Mário de Andrade: o estudo e a incorporação da cultura popular brasileira.

22 V. ANDRADE, Mário de. A arte religiosa no Brasil. São Paulo: Experimento, Giordano, 1993.

23 BRITO, Mário da Silva. História do modernismo brasileiro, 1: antecedentes da Semana de Arte Moderna. 6. ed. Rio de Janeiro: Civilização Brasileira, 1997. p. 233-234. 
Não sugerimos neste ensaio a substituição da separação radical entre Arinos e Mário por uma simples continuidade temática sem maiores conseqüências. 0 nacionalismo de Arinos e de alguns de seus companheiros de geração, como Bilac, pôde estimular um Mário de Andrade em formação nos anos 10 . Na década seguinte, uma nova fatura estética vai problematizar esse legado, que atingiu seu ápice em Macunaima (1928).

\section{Para se conhecer mais Afonso Arinos}

Depois do livro pioneiro de Tristão de Athayde, Afonso Arinos retorna em algumas histórias literárias. Lucia Miguel Pereira, em Prosa de ficção (de 1870 a 1920), de 1950, diante de uma obra exígua, tenta dimensionar a "fama" do escritor:

É pois por esparsos trabalhos de mocidade, que Arinos nos é conhecido, nove contos e um romance feito às pressas, como folhetim. Todos os que com ele privaram e se sentiram atraídos por uma personalidade que deve ter sido na verdade de grande irradiação, humana e pitoresca, doce e imprevista, possuem a convicção de que ainda haveria de fazer muito. Infelizmente, só pelo que lemos lhe podemos aquilatar do valor. E por isso parece-nos algum tanto exagerado o seu prestigio. ${ }^{24}$

Insinua-se assim que, além dos escritos, devem-se buscar as relações e atuações de Arinos para se avaliar sua importância. Por outro lado, a publicação em 1969 da Obra completa, organizada por Afrânio Coutinho - hoje preciosidade nos sebos -, colocava pela primeira vez à disposição conjuntamente não só a ficção, mas também as obras de outros gêneros, como as conferências de Lendas e tradições brasileiras ${ }^{25}$.

Alfredo Bosi, em História concisa da Literatura Brasileira (1970), antes de abordar Afonso Arinos, lança a idéia de certa continuidade, explorada no presente ensaio, entre alguns escritores do entre-séculos e os modernistas: “(...) alguns dos nossos regionalistas precederam, em contexto diferente, o vivo interesse dos modernos pela realidade brasileira total, não apenas ur-

24 PEREIRA, Lucia Miguel. Prosa de ficção: de 1870 a 1920. Belo Horizonte: Itatiaia; São Paulo: EDUSP, 1988. p. 187.

25 ARINOS, Afonso. Obra completa. Edição de Afrânio Coutinho. Rio de Janeiro: INL, Aguilar, 1969. 
bana" ${ }^{26}$. Por outro lado, limita a apreciação de Arinos em função da ficção regionalista, porém sabendo equilibrar a distância que medeia o estilo "parnasiano" e as qualidades do criador:

A presença de uma ars dictandi hoje antiquada, na fatura lingüistica do livro, não invalida o acerto descritivo nem a fluência narrativa daqueles momentos pelos quais Afonso Arinos tem permanecido na história da prosa brasileira. ${ }^{27}$

Viria de um conterrâneo de Paracatu (MG) mais um estudo monográfico: trata-se de De volta ao Sertão: Afonso Arinos e o regionalismo brasileiro (1975), de Oliveira Mello, que mescla biografia e comentários de alguns aspectos da obra, como a vegetação e o folclore ${ }^{28}$.

E não é de se estranhar que seja um historiador propriamente dito quem traz à tona o papel de Arinos, além das letras, nas primeiras décadas do século XX. Nicolau Sevcenko, em Orfeu extático na metrópole: São Paulo, sociedade e cultura nos frementes anos 20 (1992), dedica algumas páginas a Arinos, como "vértice do movimento de 'redescoberta' do Brasil 'popular', 'folclórico' e 'colonial”'²9. Apesar de mencionar indiretamente as conferências de Lendas e tradições brasileiras, através da citação de uma testemunha da época - mais uma vez, o ciclo de 1915 seria "esquecido" ou "minimizado" -, Sevcenko se centra na montagem póstuma da peça de Arinos, $O$ contratador de diamantes, em 1919. Muito do que ocorreu com a apresentação que finalizou as Lendas e tradições brasileiras se repetia: a promoção também pela Sociedade de Cultura Artística, o Teatro Municipal como palco, a participação em peso no elenco da mais fina flor da sociedade paulistana e manifestações da música popular, no caso, o Congado, com "pretos de verdade". Conclui que o espetáculo funcionou "como cristalização e como catalisador de uma fermentação nativista que adquiria densidade crescente em di-

26 BOSI, Alfredo. História concisa da Literatura Brasileira. 33. ed. São Paulo: Cultrix, 1994. p. 208.

27 BOSI, Alfredo. História concisa da Literatura Brasileira. 33. ed. São Paulo: Cultrix, 1994. p. 210.

28 MELLO, Oliveira. De volta ao sertão: Afonso Arinos e o regionalismo brasileiro. 2. ed. Rio de Janeiro: Editora Cátedra; Brasília: INL, 1981.

29 SEVCENKO, Nicolau. Orfeu extático na metrópole: São Paulo, sociedade e cultura nos frementes anos 20. São Paulo: Companhia das Letras, 1992. p. 238. 
reção aos anos $20 " 30$. Contudo, seu impulso inicial foi dado pelo próprio Afonso Arinos com as conferências Lendas e tradições brasileiras. 0 que deve ser enfatizado, na esteira das observações de Sevcenko, é o fato de esses dois eventos decisivos em torno de Arinos terem ocorrido em São Paulo, onde logo estouraria a Semana de Arte Moderna.

Em nossa dissertação de mestrado, Edição genética d'0 seqüestro da dona ausente de Mário de Andrade (2001), levantamos a hipótese de que Mário tenha sido despertado em seu interesse pela cultura popular ao comparecer às conferências de Arinos. Essa hipótese é retomada na introdução de Walnice Nogueira Galvão para a edição de Contos, a qual, por sua vez, coloca atualmente em circulação a parte significativa da obra do escritor mineiro ${ }^{31}$.

Por todas essas considerações e estudos, fica evidente a necessidade de uma biografia de fôlego de Afonso Arinos, primordial para a compreensão de vários aspectos da intelectualidade brasileira do final do século XIX e começo do século XX. A variedade dos espaços que percorreu, no Brasil e no exterior, dá a medida da riqueza de sua trajetória. A infância e a adolescência pelo interior de Minas Gerais, Paracatu, Estrela, Goiás, Rio Novo, Barbacena e São João del Rei. A estada em Ouro Preto, de 1891 a 1896, em cuja residência recebeu tanto intelectuais da cidade, quanto os exilados do Rio de Janeiro, como vimos no caso de Bilac. A vida em Paris, de 1904 a 1914, entremeada com viagens ao Brasil, onde freqüentou o salão de Eduardo Prado. As experiências finais em São Paulo: em vida, com as conferências Lendas e tradições brasileiras; e póstuma, com a encenação de 0 contratador de diamantes. Tais são exemplos de capítulos de uma biografia que enriqueceria a historiografia literária, ao rever a ruptura drástica entre o Modernismo e os movimentos que o antecederam.

30 SEVCENKO, Nicolau. Orfeu extático na metrópole: São Paulo, sociedade e cultura nos frementes anos 20. São Paulo: Companhia das Letras, 1992. p. 247.

31 CARVAlHO, Ricardo Souza de. Edição genética d'O seqüestro da dona ausente de Mário de Andrade. 2001. Dissertação (Mestrado em Literatura Brasileira). Faculdade de Filosofia Letras e Ciências Humanas da Universidade de São Paulo, São Paulo, 2001. ARINOS, Afonso. Contos. Edição de Walnice Nogueira Galvão. São Paulo: Martins Fontes, 2006, p. IXXXXVIII. 